\title{
O Direito de Retenção por Benfeitorias no Código Civil Brasileiro
}

\author{
Eustava Burgas de Oliveina \\ Advogado/RS
}

\section{Introdução}

s jurisprudentes romanos conceituavam as benfeitorias como despesa (impensae), dividindo-as em três espécies, que até hoje consagramos: necessárias, ${ }^{1}$ úteis ${ }^{2}$ e voluptuárias. ${ }^{3}$ As benfeitorias, previstas no Código Civil brasileiro, ${ }^{4}$ são obras e despesas que se fazem em bem móvel ou imóvel para conservá-lo, melhorá-lo ou embelezá-lo.

O direito de retenção surgiu no segundo período da história do direito romano, com o sistema do processo per formulas. Com o Decreto no 917, de 24 de outubro de 1890, o instituto da retenção tomou en tre nós, embora limitadamente no processo de falência, o aspecto de um direito de aplicação geral, perfeitamente disciplinado e protegido, de acordo com as mais modernas tendências, e inspirado nos preceitos do Código Federal Suíço das Obrigações, de 1881.

Promulgado o Código Civil de 1916, continuou o direito de retenção com seu aspecto tradicional e passivo de direito de defesa, assegurado de modo expresso em alguns dispositivos esparsos (arts. 516, 772, 873 , entre outros). O direito de retenção por benfeitorias, previsto no art. 516 do Código Civil, é, portanto, a faculdade le.

1. A doutrina exemplifica alguns casos de benfeitorias necessárias: a medicação de um animal doente, a desinfecção de um pomar atacado de praga, a pintura para conservação das paredes de uma casa, o telhado, o erguimento de cercas ou muros, a defesa judicial de imóvel, serviços realizados num alicerce da casa que cedeu, reconstrução de um assoalho que apodreceu, colocação de cerca de arame farpado para proteger a agricultura, o conserto de pilares de uma casa, e as despesas como colocar óleo no motor de um automóvel (Tupinambá Miguel Castro do Nascimento. "Posse e propriedade" - doutrina, p. 92; Arnaldo Rizzardo. Direito das Coisas. V.1, p. 178; Maria Helena Diniz, Código Civil Anotado, p. 73).

2. A jurisprudência traz como exemplo de benfeitoria útil o aterro de um terreno (Tribunal de Alçada do Rio Grande do Sul, $4^{\mathrm{a}}$ Câmara Civel, AC 190035014, Rel. Talai Djalma Selistre, 03.05.1990).

3. Também chamadas de voluntárias (Eulâmpio Rodrigues Filho. Código Civil Anotado, p. 330) ou voluptuosas (De Plácido e Silva Vocabulário Jurídico, v. I A-C, p. 236).

4. $O$ art. $63, \S \S 1^{0}$ a $3^{\circ}$ do Código Civil, define as três espécies de benfeitorias. 
gítima do possuidor ${ }^{5}$ de boa-fé de, independente de qualquer convenção, conservar em seu poder coisa certa, além do momento em que deveria restituí-la, a título de garantia de um crédito decorrente da realização de benfeitorias necessárias ou úteis nessa mesma coisa.

\section{Características do direito de retenção}

O direito de retenção é um direito acessório, indivisível e transmissível OLAVO DE ANDRADE, citando CARVALHO DE MENDONÇA, afirma que o direito de retenção é uma muralha que protege a obrigação. O direito de retenção, para OLAVO DE ANDRADE:

"(...) sendo uma garantia que su põe sempre um crédito principal, e surgindo com este para o garantir segue sempre as vicissitudes deste; sempre acompanha-o em seu destino; e se o crédito se extingue com ele também se extingue o direito de retenção."
Portanto, a acessoriedade do direito de retenção se deve ao fato de que ele nasce, vive e morre com a obrigação principal, que é um crédito, cuja satisfação visa assegurar.

O direito de retenção é também indivisível, pois a satisfação completa do crédito é condição indispensável para a restituição da coisa. ${ }^{7}$ Isto significa que o retentor tanto poderá reter o objeto inteiramente para uma parte do crédito, como para o pagamento integral do que lhe é devido pode reter uma parte do objeto.

Por último, o direito de retenção é, como direito real, ${ }^{8}$ transmissível tanto a título universal como singular. Para ANTO. NIO FARIA CARNEIRO PACHECO, a transmissão do direito de retenção tem que ocorrer conjuntamente com o crédito (por isso que se trata de um direito acessório), pois a relação de conexidade entre a coisa e o crédito é um dos requisitos indispensáveis para a existência do direito de reten-

5. Arnoldo Medeiros da Fonseca entende que 0 exercício do direito de retenção não requer a posse. Para ele, basta a detenção legítima da coisa alheia (Arnoldo Medeiros da Fonseca. Direito de Retenção, p. 116). Porém, o entendimento atual é no sentido de que a configuração da posse é necessária, tanto é que o art. 516 do Código Civil fala em "possuidor", e não mero detentor.

6. ANDRADE, Olavo de. Notas sobre o direito de retenção, pp. 35-36.

7. Olavo de Andrade cita as conseqüências práticas que resultam da indivisibilidade do direito de retenção: "a) pelo simples fato de haver recebido um pagamento parcial, não se presume ter o credor renunciado o seu direito de retençáo relativamente a uma parte proporcional do objeto ainda mesmo quando este seja divisível; assim também, pelo simples fato de haver abandonado uma parte da coisa ou objetos retidos não perde o direito de retenção para uma parte correspondente do seu crédito, gozando, pelo contrário desse direito sobre a parte conservada até inteiro pagamento; b) por morte do retentor, tendo o crédito garantido sido dividido entre seus herdeiros, nenhum destes, ainda que haja recebido a sua parte, pode restituir ao devedor a coisa retida com prejuízo de seus co-herdeiros que não tenham sido pagos, pois que cada herdeiro pode, só pela sua parte no crédito, exercer esse direito sobre a totalidade da coisa ou das coisas que ele onera; $c$ ) morto o devedor, e partilhada a dívida entre seus herdeiros, nenhum destes, ainda que haja pago a sua parte, poderá exigir a restituição no todo ou em parte da coisa retida para pagamento da dívida primitiva; o credor exerce a retenção enquanto não houver recebido pagamento integral do que por todos os herdeiros do devedor Ihe seja devido". (Olavo de Andrade. Notas sobre o direito de retençăo, pp. 34-35)

8. Há grande divergência doutrinária acerca da natureza jurídica do direito de retençăo. Uns entendem que se trata de um direito pessoal, outros um direito real, outros um direito pessoal oponivel a terceiros, outros um direito real sui generis, e outros ainda o consideram um direito de natureza variável (real ou pessoal, conforme o caso). Entretanto, a corrente majoritária entende ser 0 direito de retenção um direito real.

Revista da Faculdade de Direito da UFRGS, v. 18, 2000

ção. ${ }^{9}$ Por último, lembre-se que a cessão do crédito deve revestir as formalidades legais (arts. 1.065 a 1.078 do Código Civil). ${ }^{10}$

\section{Direito de retenção e acessões} industriais

Em primeiro lugar, é mister que se estabeleça claramente a distinção entre benfeitorias e acessões industriais (plantações e construções). Benfeitorias são obras e despesas feitas pelo homem na coisa, com o intuito de conservá-la, melhorá-la ou embelezá-la; as acessões são obras que viram coisas novas, diferentes, e que vêm aderir à coisa anteriormente existente. $\mathrm{Ou}$ seja, as benfeitorias têm cunho complementar, ao passo que as acessões industriais são coisas novas.

Os tribunais pátrios com muita freqüência divergem quanto ao tratamento a ser dado às benfeitorias e às acessões industriais. Alguns doutrinadores entendem que o instituto do direito de retenção só deva ser aplicado às benfeitorias. Outros, porém, afirmam que a retenção também pode ser estendida às acessões industriais. Esta di- vergência doutrinária e jurisprudencial existente nos conduz, então, a analisarmos quais são os argumentos de uma e de outra corrente.

Há uma tendência jurisprudencial no sentido de negar o direito de retenção por acessões. ${ }^{11}$ Este é o entendimento de SILVIO RODRIGUES, sustentando que não cabe retenção por acessões, pois a lei só autoriza a retenção quando se trata de benfeitorias. ${ }^{12}$ Esta doutrina baseia-se na distinção técnica entre benfeitorias e acessões industriais formulada nas obras de ORLANDO GOMES ${ }^{13}$ e Washington de BARROS MONTEIRO, ${ }^{14}$ principalmente (é a corrente minoritária).

Outra doutrina, entendendo ser cabível o direito de retenção pelas acessões, é a majoritária, onde vale citar JOSÉ GUILHERME BRAGA TEIXEIRA:

"Entrementes, se o legislador conferiu ao possuidor de boa-fé o direito de retenção da coisa principal, até ser indenizado das benfeitorias necessárias e úteis, foi omisso em relação à hipótese de retenção pelas construções e plantaçōes. Dir-se-á, pugnando em

9. As condiç̃oes gerais de existência do direito de retenção são: posse de coisa alheia, crédito certo e exigivel do retentor, relação de conexidade entre a coisa e o crédito, e inexistência de exclusão convencional ou legal do direito de retenção.

10. Conforme o art. 1.071 do Código Civil, se o devedor não for notificado da cessão de crédito e pagar ao credor primitivo, extinguese 0 direito de retenção.

11. Tribunal de Alçada do Rio Grande do Sul, $1^{2}$ Câmara Cível, AC 190019554, Rel. Luiz Felipe Azevedo Gomes, 17.04.1990; Tribunal de Justiça do Rio Grande do Sul, $6^{a}$ Câmara Cível, AC 597055334, Rel. Osvaldo Stefanello, 04.03.1998; Tribunal de Justiça do Rio Grande do Sul, $15^{\mathrm{a}}$ Câmara Cível, AC 599346384, Rel. Ricardo Raupp Ruschel, 22.09.1999; $1^{9}$ Tribunal de Alçada Cível de São Paulo, 4ª Câmara Cível, Al 393.871-4, Rel. Barbosa Pereira, 14.06.1989; Tribunal de Justiça do Paraná, $8^{\mathrm{a}}$ Câmara Cível, AC 38227200, Rel. Lauro Laertes de Oliveira, 17.03.1999; Tribunal de Justiça do Paraná, $4^{\mathrm{a}}$ Câmara Cível, AC 12306800, Rel. Ronald Accioly, 06.03.1991; Tribunal de Justiça do Paraná, $2^{\mathrm{a}}$ Câmara Civel, AC 12481600, Rel. Sydney Zappa, 17.04.1991; Tribunal de Justiça do Paraná, 1a Câmara Cível, AC 05734100, Rel. Oto Sponholz, 20.02.1990; Tribunal de Alçada do Paraná, Câmara Cível, AC 0115773-3, Rel. Mendes da Silva, 29.03.1999; RT 616/144.

12. RODRIGUES, Silvio. Direito Civil, p. 102, v. 5 .

13. GOMES, Orlando. Direitos Reais, p. 69 .

14. MONTEIRO, Washington de Barros. Curso de Direito Civil, v. 1, pp. 151-152. 
sentido negativo, que o fato de haver referido tal direito àquelas benfeitorias de maneira expressa é significativo de que só a ela desejou conferir o direito de retenção, pois se quisesse contemplar igual direito às acessões industriais tê-lo-ia feito igualmente de modo expresso, no art. 547. De nossa parte, entendemos que ao possuidor de boafé deverá ser conferido o direito de retenção pelas construções e plantações, até ser indenizado dos respectivos valores, como medida de eqüidade. (...) Estas acessões industriais, ainda que se possam, no rigor técnico da expressão, distinguir das benfeitorias, obedecem a normas semelhantes. Equiparam-se a benfeitorias úteis, e o Código, no art. 548, lhes dá esse nome."15

Esta corrente que entende ser cabí vel o direito de retenção pelas acessões in dustriais é reforçada, entre outros, por ARRUDA ALVIM e AMÍLCAR DE CAS. TRO. O entendimento jurisprudencial majoritário é neste sentido. ${ }^{16}$

Embora, de acordo com a corrente majoritária, ${ }^{17}$ haja distinções entre benfeitorias e as denominadas acessões in dustriais, há, igualmente, semelhanças, entre as quais podemos destacar: 1) constituem, ambas, coisas acessórias, 2) produzem, via de regra, como coisas novas que são, fator preponderante de maior utilidade da coisa principal e elemento de conservação, 3) são produtos de participação direta do possuidor ou detentor e 4) a perfeição de seu processo de integração com a res principalis fá-las perder a identidade, tornando-as, regra geral, irremovíveis.

\section{Direito de retenção e exceptio non adimpleti contractus}

$O$ instituto da exceptio non adimpleti contractus não era conhecido no direito romano. Foi criado pelos canonistas e aperfeiçoado pelos post-glosadores, tendo caído em desuso a partir do século XVI. Quando renasceu, a exceptio começou a desenvolver-se sob a capa de outras figuras jurídicas (particularmente a capa do direito de retenção). ARNOLDO MEDEIROS DA FONSECA, citando CLÓVIS BEVILÁQUA, afirma que a exceptio é uma modalidade do direito de retenção. Porém, JOÃO CALVÃO DA SILVA argumenta que, embora sejam figuras próximas, usadas pelo credor como meio defensivo e temporário de conservar o que deve para garantir e constranger o devedor a cumprir

15. José Guilherme Braga Teixeira. "A indenização das benfeitorias e acessões industriais ao possuidor de boa-fé e 0 direito de retenção", in Revista dos Tribunais, v. 60, pp. 168-169.

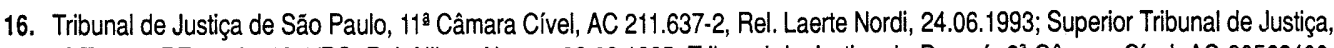
$3^{\mathrm{a}}$ Turma, REsp 59.669-6/RS, Rel. Nilson Naves, 28.08.1995; Tribunal de Justiça do Paraná, $2^{\mathrm{a}}$ Câmara Cível, AC 30562400,

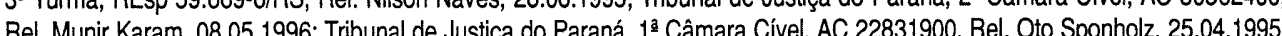
Tribur Tribunal de Alçada do Paraná, 8 câmara Civel, AC O100128-5, Rel Dulce Marla Cecconi, 09.02.1958, Supremo Tribunal Fedea, $3^{\mathrm{a}}$ Turma, REsp 28.489 Rel. Eduardo Ribeiro, 19.10.1993; Tribunal de Justiça de Săo Paulo, 24.05.1974, in RT 46959, Trbunal de Alçada do Rio Grande do Sul, 2 Camara Civel, AC 5.536, Rel. Hermann Homem de Carvalho Roenick, 29.05.1973, in RT 458231, Thunal de Justiça do Rlo Grande do Su, 50 CAmara Clvel, AC 597223007, Rel Araken de Assis, 04.12.1997, Thbunal de Jusiļ̧a do Rio Grande do Sul, 2 Camara Civel, AC 185003662, Re. Andrade Xavier, 12.03.1985; RT 589/221, 451/228, 472/192, 479/261, 361/126, 321/233, 437/229, e 404/150.

17. Caio Mário da Silva Pereira, Carlos Alberto da Costa Dias, Eulâmpio Rodrigues Filho, Orlando Gomes, Washington de Barros Monteiro e Maria Helena Diniz.

Revista da Faculdade de Direito da UFRGS, v. 18, 2000

a sua prestação, os institutos não se confundem. ${ }^{18}$

Existem quatro diferenças básicas entre o direito de retenção e a exceptio. Em primeiro lugar, a relação sinalagmática que caracteriza a exceptio, pela qual as obrigações recíprocas devem ser cumpridas simul taneamente, não se aplica ao direito de retenção. ${ }^{19}$ Em segundo lugar, a exceptio não se aplica aos contratos bilaterais imperfeitos, domínio em que o direito de retenção surge com freqüência. ${ }^{20}$

Verificamos ainda uma terceira diferença entre os institutos em exame: a exceptio não pode ser afastada mediante a prestação de garantias, ao passo que o di reito de retenção não pode ter lugar quando a outra parte preste caução suficiente.

18. SILVA, João Calvăo da. Cumprimento e sanção pecuniária compulsória, p. 348

19. Citaremos um exemplo bem elucidativo: "Ao reter a coisa (por exemplo, 0 automóvel), o garagista visa obter da contraparte 0 cumprimento da obrigação principal, o preço da reparação do automóvel, suspendendo, para o efeito, a sua obrigação secundária de (restituiçăo e) entrega do automóvel detido, a qual não é motivo determinante da obrigação de pagar o custo da reparação. A causa da obrigação principal de pagamento do preço por parte do dono do automóvel é a atividade de reparação que o garagista teve de desenvolver, sua obrigação principal recíproca e correspectiva daquela. Daí que, cumprida a obrigação principal de reparação do automóvel, o garagista não possa já invocar a exceptio non adimpleti contractus, que, por definição, se traduz na suspensão do cumprimento da obrigaçấo correspectiva de outra obrigação não cumprida e enquanto não cumprida. Tudo o que resta ao garagista, cumpridor da obrigação principal de reparação, é não cumprir a obrigação secundária de entregar o automóvel por si detido, que não é a causa da obrigação do preço. E pode legalmente não cumpri-la, enquanto o dono do automóvel não pagar o preço da reparação, porque isso é forma de garantir e constranger o proprietário a solver o seu débito. Para isso retém o automóvel, usando o direito de retenção que a lei lhe confere, ultimum subsidium coercitivo privado que the resta, visto que não pode usar já a exceptio non adimpleti contractus por ter cumprido a sua obrigação principal de reparação, causa determinante da correlativa obrigação de pagamento do preço. Neste sentido, pode-se dizer quer o direito de retenção é sucedâneo ou substituto da exceptio non adimpleti contractus". (João Calvão da Silva. Cumprimento e sançăo pecuniária compulsória, pp. 348-349).

20. "(...) a bilateralidade era perfeita quando o contrato produzia obrigaçōes principais para todos os contratantes, como na compra e venda, e imperfeita, quando, no momento da formaçáo do contrato, só existiam obrigaçōes principais para um dos contratantes, mas, no decorrer de sua execução, nasciam obrigaçōes para o outro, como no caso de depósito, em que o depositante ficava obrigado a pagar o despendido pelo depositário com a guarda da coisa depositada (...), e do comodato, em que poderá surgir para o comodatário o direito de reclamar do comodante indenização de certas despesas". (Washington de Barros Monteiro. Curso de Direito Civil, v.5, p.24)

21. Assim, a exceptio pode ser invocada perante o devedor de obrigação de facere, fungivel ou infungivel, e de obrigaçáo de prestação de coisa.

22. SILVA, João Calvão da. Cumprimento e sanção pecuniária compulsória, p. 350

23. SILVA, De Plácido e. Vocabulário Jurídico, v. IV, p. 1374. 
quanto subsistir seu crédito. Decorrentes deste direito principal, o retentor possui outros direitos, quais sejam:

"19) repelir pela força, nos limites da necessidade, a violência alheia, tendente a privá-lo da detenção da coisa, e mesmo por tal meio recuperá-la, no caso de esbulho, desde que o desforço seja praticado in continenti; $2^{\circ}$ ) Usar das ações possessórias para proteger a sua posse; 3ํ) Repetir a coisa que já detinha e haja restituído por erro, uma vez que o prove; $4^{\circ}$ ) Reter os frutos $d a$ coisa, por aplicação da regra de que o acessório segue a condição jurídica do principal; 5o) Exigir reembolso das despesas que houver feito para conservação da coisa retida e o ressarcimento do prejuizo decorrente de vício dela, do qual não haja sido avisado, uma vez que tivesse razão de o ignorar."24

Como conseqüências desses direitos, ARNOLDO MEDEIROS DA FONSECA elenca duas: $1^{a}$ ) Não pode o retentor usar da coisa retida, salvo se houver qualquer convenção acessória que lhe permita servir-se dela; ${ }^{25}$ e $2^{a}$ ) Não tem, em regra, o retentor direito de apropriar-se dos frutos da coisa para vendê-los e levar o preço obtido a conta do seu crédito. ${ }^{26}$

Sujeito destes direitos, o retentor, igualmente, é sujeito de quatro obrigações básicas:

“1) Empregar na guarda e conservação da coisa retida a diligência exigida pela sua natureza (...);2) Restituir a aludida coisa, com os seus frutos e acessões, uma vez pago do que lhe for devido (...); 3) Entregar o que sobeje do preço, quando o crédito for satisfeito em virtude da venda $d a$ coisa retida, nos casos excepcionais em que o retentor tem a faculdade de realizá-la, ou quando o devedor lhe autorizar, mediante procuração especial; e 4) Indenizar o prejuizo resultante das perdas e deteriorações da coisa, ocorridas por culpa sua (...)."27

A obrigação de restituir a coisa cessa, porém, total ou parcialmente, se a coisa perecer, ou deteriorar-se, sem culpa do retentor. ${ }^{28}$ Este é o entendimento de ARNOLDO MEDEIROS DA FONSECA e de ANTONIO FARIA CARNEIRO PACHECO.

Ressalte-se que aos direitos e obrigações do retentor correspondem os do devedor, o que também se aplica a seus herdeiros, como sucessores a título universal. ANTONIO FARIA CARNEIRO PACHECO, por derradeiro, afirma que a principal obrigação do retentor é restituir a coisa com todos os seus acessórios, ${ }^{29}$ logo que seja inteiramente pago de seu crédito, inclusive as despesas que haja feito com a conservação da coisa. ${ }^{30}$

24. FONSECA, Arnoldo Medeiros da. Direito de retenção, pp. 280-281.

25. A lei silencia a respeito, mas é esta a conclusão que chegam os autores por aplicação analógica das disposiçōes relativas ao penhor e ao deposito.

26. Com relação a esta segunda consequêencia há uma exceção, quando se tratar de frutos que não possam ser conservados, pois seria um absurdo deixá-los perecer sem proveito para ninguém.

27. FONSECA, Arnoldo Medeiros da. Direito de retençăo, pp. 287-288.

28. Vide arts. 869 e 871 do Código Civil. 29. Tanto os acessorios existentes ao tempo em que surgiu o direito de retenção, como também os que posteriormente acresceram
à coisa.

30. PACHECO, Antonio Faria Carneiro. Do direito de retenção, p. 90.

\section{Conclusão}

O direito de retenção por benfeitorias, como vimos, também é aplicado às acessões industriais, entendendo os tribunais que, embora tecnicamente sejam institutos jurídicos diversos, a ambos se aplicam as regras do direito de retenção. A jurisprudência é majoritária neste sentido.

Na nossa opinião, não se deve aplicar o direito de retenção nas acessões industriais, pois se o legislador assim o quisesse teria disposto expressamente no Código Civil, e assim não o fez. Tendo o legislador conferido o direito de retenção somente pelas benfeitorias, não há que se interpretar extensivamente o art. 516 do Código Civil para aplicar o direito de retenção também no instituto das acessões. Mas esta divergência jurisprudencial não vai cessar por ora, com certeza ainda irá pairar por muito tempo nos tribunais pátrios.

\section{Bibliografia}

ANDRADE, Olavo de. Notas sobre o Direito de Retenção. São Paulo: Saraiva, 1992.

CASTRO, Amílcar de. Comentários ao Código de Processo Civil. Rio de Janeiro: Forense, 1983.

DIAS, Carlos Alberto da Costa. "Retenção por benfeitorias". In Revista de Processo. V. 74, São Paulo, 1994, pp. 179-184.

DINIZ, Maria Helena. Código Civil Anotado. São Paulo: Saraiva, 1995.
FONSECA, Arnoldo Medeiros da. Direito de Retenção. 3. ed., Rio de Janeiro: Forense, 1957.

GOMES, Orlando. Direitos Reais. 7. ed., Rio de Janeiro: Forense, 1980.

MONTEIRO, Washington de Barros. Curso de Direito Civil. V. I, III e V, 20. ed., São Paulo: Saraiva, 1985.

NASCIMENTO, Tupinambá Miguel Castro do. "Posse e Propriedade" (doutrina). Rio de Janeiro: Aide, 1986.

PACHECO, Antonio Faria Carneiro. Do direito de retenção. Rio de Janeiro: Jacinto Ribeiro dos Santos, 1912.

PEREIRA, Caio Mario da Silva. Instituições de Direito Civil. V. IV, 11. ed., Rio de Janeiro: Forense, 1994.

RIZZARDO, Arnaldo. Direito das Coisas. V.1, Rio de Janeiro: Aide, 1991.

RODRIGUES, Silvio. Direito Civil. V. 4 e 5, 18. ed., São Paulo: Saraiva, 1989.

RODRIGUES FILHO, Eulâmpio. Código Civil Anotado. 2. ed., Porto Alegre: Síntese, 1998.

SILVA, João Calvão da. Cumprimento e Sanção Pecuniária Compulsória. Coimbra: Almedina, 1987.

SILVA, De Plácido E. Vocabulário Jurídico. V. I, II e III, 4. ed., São Paulo: Forense, 1975.

TEIXEIRA, José Guilherme Braga. "A indenização das benfeitorias e acessões industriais ao possuidor de boa-fé e o direito de retenção". In Revista dos Tribunais. V. 60, São Paulo, abr./1992, pp.165-170. 